\title{
Norepinephrine Uptake by Hypothalamic Tissue from the Rat Related to Feeding
}

\author{
J. VAN DER GUGTEN AND J. L. SLANGEN \\ Rudolf Magnus Institute for Pharmacology, University of Utrecht, Medical Faculty \\ Vondellaan 6, Utrecht, The Netherlands
}

(Received 6 February 1975)

\begin{abstract}
VAN DER GUGTEN, J. AND J. L. SLANGEN. Norepinephrine uptake by hypothalamic tissue from the rat related to feeding. PHARMAC. BIOCHEM. BEHAV. 3(5) 855-860, 1975. - Norepinephrine (NE) uptake by rat hypothalamus in vitro was studied in relation to food intake. Significant daily variations in NE uptake were observed in caudal hypothalamus from freely feeding rats. A maximal elevation occurred at the beginning of the night when food intake is also increasing to a maximum. NE uptake by caudal hypothalamus from relatively hungry rats previously adjusted to restricted feeding during the daytime was enhanced in afternoon and evening when compared with uptake by tissue from ad lib feeding animals. Determination of NE uptake by caudal hypothalamus from freely feeding individual rats and registration of individual meals taken by these rats revealed a relation between hypothalamic neuronal activity and the feeding pattern of the rat. A positive correlation was observed between NE uptake in vitro and feeding rate during a 2 to 4-hr interval. It also appeared that NE uptake by caudal hypothalamus is dependent on the time elapsed after the last meal. The data were evaluated in view of physiological studies concerning the onset of feeding and the hypothesis of hypothalamic adrenergic control of food intake.
\end{abstract}

Norepinephrine uptake Caudal hypothalamus Circadian rhythm Food deprivation Restricted feeding Meal pattern Adrenergic feeding system Food intake regulation

PREVIOUS studies suggest a role for central adrenergic systems in the regulation of feeding behavior. Intrahypothalamic administration of L-norepinephrine (NE) has been shown to induce eating in food satiated rats $[2,12]$. It has been found that only $\alpha$-adrenergic receptor agonists elicit eating in satiated rats and that this effect can be prevented by central application of an $\alpha$-adrenergic blocking agent and not by a $\beta$-adrenergic antagonist $[3,25]$. It has also been shown that inhibitors of the reuptake of NE into nerve terminals augment the eating response to exogenous NE in satiated rats $[3,25]$, whereas intrahypothalamic administration of an uptake inhibitor enhances food intake in food deprived rats [21]. These findings can be interpreted as evidence that adrenoceptors in the hypothalamus are components of a feeding system. In addition, other central adrenergic mechanisms may play a role in the control of ingestive behavior $[18,24]$.

If a hypothalamic adrenergic system is involved in the regulation of feeding in the rat the activity of such a system should change in relation to the need for food. The present study deals with the relation between NE uptake by hypothalamic tissue in vitro and feeding. As there is a circadian rhythm in food intake, daily variations in NE uptake by brain tissue from freely feeding animals were investigated. The effects of altered feeding conditions on this biochemical parameter were also studied. Finally, data concerning the relation between hypothalamic NE uptake and the individual feeding pattern of the rat are presented.

METHOD

\section{Animals}

Male Wistar rats weighing $200-250 \mathrm{~g}$ at the time of decapitation were used. The animals were adjusted either to normal lighting conditions (lights on from 7:00 to 19:00 $\mathrm{hr}$ ) or to a reversed light-dark schedule (lights on from 19:00 to $7: 00 \mathrm{hr}$ ) from 21 days of age. During the last 3 dark periods of each experiment the room was scarcely illuminated with red lights. Rats maintained on the normal lighting schedule were housed individually in wired metal cages during the last $10-14$ days of an experiment. Rats maintained on the reversed light-dark schedule were housed individually for the last 3 days. During individual housing all animals were handled at least once a day at varying times. Room temperature was automatically kept at $22-24^{\circ} \mathrm{C}$

\footnotetext{
${ }^{1}$ The investigations were supported in part by the Foundation for Medical Research FUNGO which is subsidized by the Netherlands Organization for the Advancement of Pure Research (ZWO). The authors are indepted to Mr. Kees Broekman for his valuable technical assistance.
} 


\section{Procedure}

All animals had free access to water. Muracon I $10 \mathrm{~mm}$ food pellets ( 25 percent protein, 60 percent carbohydrate dry weight) were available ad lib unless otherwise noted. Food intake was measured by offering a known amount of food and weighing the portion left in the cage.

For the determination of daily variations in hypothalamic NE uptake, rats kept under normal lighting conditions were decapitated at 4-hr intervals within $24 \mathrm{hr}$.

Groups of rats subjected to different feeding conditions and kept on a normal lighting schedule were decapitated at 2 times of day. Two groups of animals had been maintained on a schedule by which food supply was restricted to a daily 2- or 8-hr period during the last 10-14 days of the experiment. Other groups had been deprived of food for the first time from 17:00 hr on the day of decapitation or from 17:00 hr on the previous day.

The relation between hypothalamic NE uptake and individual meal pattern was studied in rats adjusted to a reversed light-dark schedule. Individual meals were registered by means of observation. All animals were decapitated within $2 \mathrm{hr}$.

NE uptake determination. Immediately after the decapitation of a rat, brains were removed and dissected. The hypothalamus [16] was divided into a rostral and caudal part, both weighing about $20 \mathrm{mg}$. Each part was cut in half along the midline, both halves being used for transmitter uptake determination in duplo. Tissue was chopped into $2.0 \times 0.3 \times 0.3 \mathrm{~mm}$ pieces by means of a Mcllwain device, weighed and transferred into $2.0 \mathrm{ml}$ of incubation medium at $0^{\circ} \mathrm{C}$. The medium was composed of $118.0 \mathrm{mM} \mathrm{NaCl}, 4.7$ $\mathrm{mM} \mathrm{KCl}, 1.7 \mathrm{mM} \mathrm{CaCl}_{2}, 1.2 \mathrm{mM} \mathrm{MgSO}_{4}, 1.2 \mathrm{mM} \mathrm{KH}_{2}$ $\mathrm{PO}_{4}, 25.0 \mathrm{mM} \mathrm{NaHCO}, 11.1 \mathrm{mM}$ glucose, $1.3 \mathrm{mM}$ ethylenediaminetetraacetic acid (disodium salt) and $1.1 \mathrm{mM}$ ascorbic acid [26]; it was saturated with 95 percent $\mathrm{O}_{2}-5$ percent $\mathrm{CO}_{2}$ and adjusted to $\mathrm{pH} 7.4$ before use. After 20 min of preincubation at $37^{\circ} \mathrm{C}$, tissue was incubated with $\mathrm{L}-\left[7-{ }^{3} \mathrm{H}\right]$ norepinephrine $\left({ }^{3} \mathrm{H}-\mathrm{NE}\right)$ (Radiochemical Centre, Amersham) at a concentration of $3 \times 10^{-8} \mathrm{M}(5-10$ $\mathrm{Ci} / \mathrm{mmole}$ ) for $30 \mathrm{~min}$ at $37^{\circ} \mathrm{C}$ in a Dubnoff metabolic shaker. The incubation was stopped by rapid filtration of the medium through premoistened cellulose nitrate filters (BA 85; Schleicher and Schüll, Dassel, W. Germany) under suction. Filters and tissue were washed twice with $5 \mathrm{ml}$ of sodiumchloride solution $(0.9$ percent, $w / v)$ at $0^{\circ} \mathrm{C}$, transferred into counting vials and solubilized by equilibration with $1 \mathrm{ml}$ of Soluene 350 (Packard Instrument Corporation, Inc., Downers Grove, Ill.) at $40^{\circ} \mathrm{C}$ for $16 \mathrm{hr}$. After successive addition of $0.1 \mathrm{ml}$ of propan-2-ol and $0.1 \mathrm{ml}$ of hydrogenperoxide ( 30 percent, w/w) the vials were kept at $40^{\circ} \mathrm{C}$ for another $60 \mathrm{~min}$ in order to reduce quenching. Ten $\mathrm{ml}$ of toluene containing 2,5-diphenyloxazole ( 0.4 percent, $\mathrm{w} / \mathrm{v}$ ) were added and radioactivity was measured by liquid scintillation spectrometry. External standards were used in order to correct for counting efficiency. Blanks were obtained from tissue incubated with ${ }^{3} \mathrm{H}-\mathrm{NE}$ at $0^{\circ} \mathrm{C}[1]$. Under the present conditions $\mathrm{NE}$ accumulation was linear up to at least 30 min of incubation.

Adrenal corticosteroid production. In some experiments the adrenals were removed immediately after the animal had been killed. They were used for determination of corticosteroid production in vitro [29].

Statistical analysis. Statistical significance of the difference between mean values was calculated by Student's t- test. Correlation between 2 variables was determined by means of second order regression analysis and computation of Pearson's correlation coefficient ( $r$ ).

\section{RESULTS}

\section{Daily Variations}

No significant differences were observed in NE uptake by chopped rostral hypothalamic tissue from ad lib feeding rats kept on a normal light-dark schedule and decapitated at different times of day. However, in vitro NE uptake by caudal hypothalamus from these animals exhibited significant variations within $24 \mathrm{hr}$ (Fig. 1, upper panel). A circadian rhythm with a maximum at 21:00 hr and minimal values at 5:00 and 17:00 hr was evident. The greatest change in transmitter accumulation was observed between 17:00 and 21:00 hr. This elevation occurred in the period when also the increase in food intake is maximal (Fig. 1, lower panel).

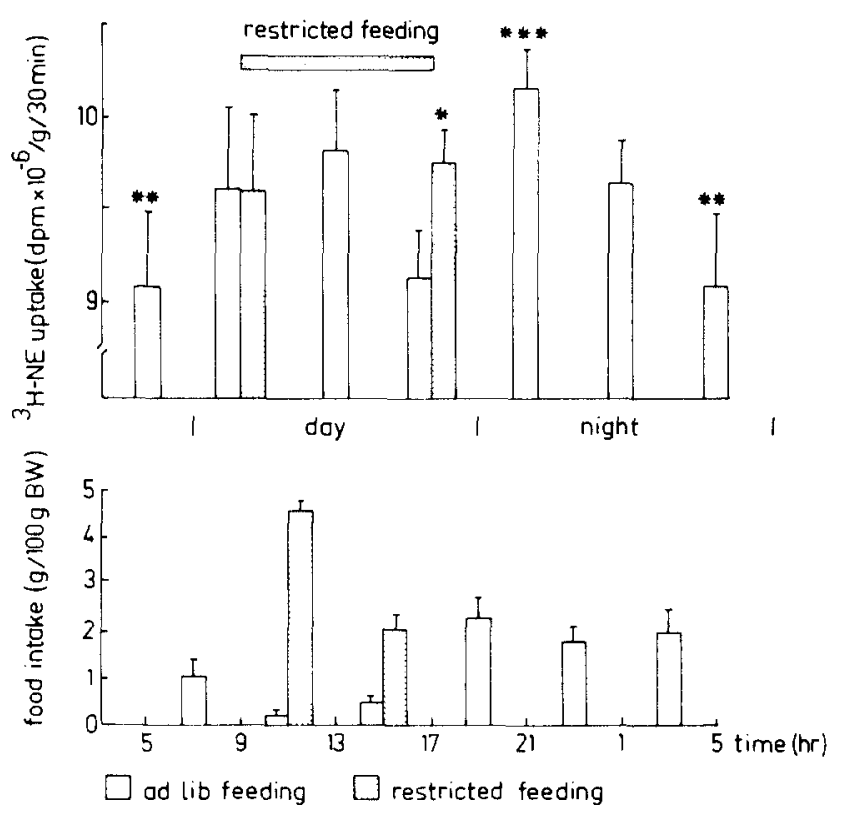

FIG. 1. Daily variations in norepinephrine uptake by caudal hypothalamus from rats with ad lib or restricted daily access to food and in food intake. Each bar represents mean \pm SEM of 5 or 6 determinations in duplo. ${ }^{*} p<0.025 ;{ }^{* *} p<0.025$, different from ad lib, $21 \mathrm{hr} ; * * * p<0.01$, different from ad lib, $17 \mathrm{hr}$.

\section{Feeding Conditions}

Relatively hungry rats maintained on a schedule of restricted feeding from 9:00 to $17: 00 \mathrm{hr}$ showed an increase in NE uptake by caudal hypothalamus at 17:00 when compared with freely feeding animals (Fig. 1).

In order to investigate a possible involvement of stress factors and thus of the pituitary-adrenal system in the changes observed for the hungry rats, in vitro corticosteroid production by adrenals from ad lib feeding rats and animals adjusted to daily restricted feeding was determined at 6 -hr intervals within $24 \mathrm{hr}$. No significant differences were observed between these groups at any time (Table 1). Both 


\section{TABLE 1}

IN VITRO CORTICOSTEROID PRODUCTION BY ADRENALS FROM RATS WITH AD LIB OR RESTRICTED DAILY ACCESS TO FOOD

\begin{tabular}{|c|c|c|}
\hline $\begin{array}{l}\text { Time of Day } \\
(\mathrm{hr})^{*}\end{array}$ & $\begin{array}{c}\text { Ad Lib } \\
\text { Feeding Group }\end{array}$ & $\begin{array}{c}\text { Restricted } \\
\text { Feeding Group } \dagger\end{array}$ \\
\hline $9: 00$ & $6.21 \pm 0.52(6) \ddagger$ & $6.85 \pm 0.62(6)$ \\
\hline $15: 00$ & $6.74 \pm 1.01$ & $6.52 \pm 0.89$ \\
\hline $21: 00$ & $9.05 \pm 1.60(6) \S$ & $9.91 \pm 1.65(6) \S$ \\
\hline $3: 00$ & $8.73 \pm 0.81$ & $9.31 \pm 1.63(6)$ \\
\hline
\end{tabular}

${ }^{*}$ Lights were on from 7:00 to 19:00 hr.

† Daily feeding period from 9:00 to $17: 00 \mathrm{hr}$.

$\ddagger \mu \mathrm{g}$ corticosteroid $/ 100 \mathrm{mg} / \mathrm{hr}$ (mean $\pm \mathrm{SEM}$ ); number of rats in parentheses.

$\S$ Combined night values were significantly different from combined daytime values for each group of animals $(p<0.025)$.

groups showed nonstress values during the daytime and also the wellknown increase of this parameter in the night.

Because of the appearance of rapid alterations both in ${ }^{3} \mathrm{H}$-NE uptake by caudal hypothalamus and in food intake of freely feeding rats in late afternoon and early evening, the relation between both parameters during this period was further studied. Animals subjected to a number of different feeding conditions were decapitated at 16:00 or 21:00 hr. NE uptake by caudal hypothalamic tissue from ad lib feeding rats at 21:00 hr was significantly different from NE uptake at 16:00 hr (Fig. 2). Transmitter uptake by tissue obtained from animals which had been adjusted to daily restricted feeding from 15:00 to 17:00 hr, however, was quite different from ad lib control values. At 16:00 hr NE uptake by caudal hypothalamus from animals maintained on this feeding schedule was significantly increased compared with uptake by tissue from ad lib feeding animals. It should be noted that on the day of decapitation the former animals had not received any food at 15:00 hr and thus were hungry at the time of decapitation. Experimental animals sacrificed at 21:00 hr had been supplied with food from 15:00 hr. In the period from 15:00 to 17:00 hr they had eaten $8.6 \pm 0.2 \mathrm{~g} / 100 \mathrm{~g}$ body weight $(\mathrm{BW})$ - which was the stabilized mean amount of food consumed by animals on the 2-hr feeding schedule - and in the period from 17:00 hr until decapitation they had consumed an additional $4.7 \pm 0.3 \mathrm{~g} / 100 \mathrm{~g} \mathrm{BW}$. Both these amounts were significantly larger than the quantities of food eaten by freely feeding animals during the same intervals (cf. Fig. 1) and therefore it can be assumed that the experimental group of animals decapitated at 21:00 hr was more in need of food than ad lib controls. In vitro NE uptake by caudal hypothalamus from these relatively hungry animals was significantly increased compared with ad lib control values (Fig. 2).

NE uptake by caudal hypothalamic tissue from rats not accustomed to a feeding schedule and deprived of food for $23 \mathrm{hr}$ tended to be increased when compared with uptake by tissue from ad lib feeding animals sacrificed at 16:00 hr, whereas no difference was observed between NE uptake by tissue from animals deprived of food for $28 \mathrm{hr}$ and the ad

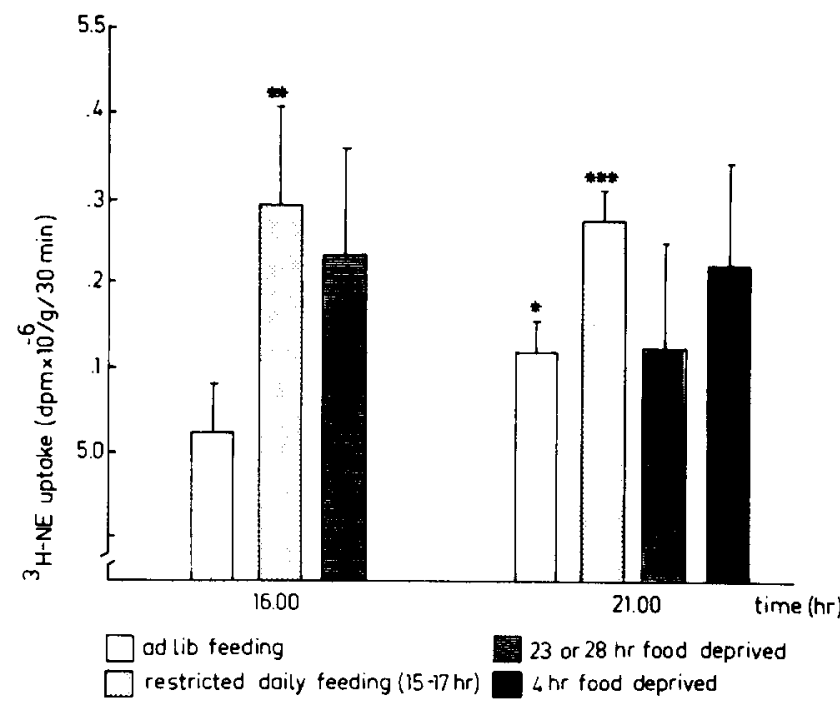

FIG. 2. Norepinephrine uptake by caudal hypothalamic tissue from rats subjected to different feeding conditions. Each bar represents mean \pm SEM of 6 determinations in duplo. Rats accustomed to restricted daily feeding and sacrificed at 16:00 hr had not received any food on the day of decapitation whereas rats from the same group but decapitated at 21:00 hr had been supplied with food from 15:00 hr. ${ }^{*} p<0.05,{ }^{* *} p<0.025$, different

from ad lib, $16 \mathrm{hr} ; * * * p<0.01$, different from ad lib, $21 \mathrm{hr}$.

lib control value at 21:00 hr. NE uptake by caudal hypothalamus from $4 \mathrm{hr}$ food deprived rats slightly tended towards an increase compared with uptake by tissue from ad lib feeding animals decapitated at 21:00 hr.

\section{Meal Pattern}

Hypothalamic NE accumulation was also studied in relation to the individual meal pattern of rats which had free access to food. The biochemical and behavioral parameters were determined during the first half of the dark period. A significant positive correlation was found between NE uptake by caudal hypothalamus in vitro and the rate of food intake throughout a 2 - to 4-hr interval immediately before decapitation (Fig. 3, upper panel) (When no feeding had been observed during the last $3 \mathrm{hr}$ the corresponding animal was excluded from regression analysis). From the equations of the regression lines a theoretical NE uptake value could then be assigned to each particular rate of food intake. Deviations in hypothalamic NE uptake from this theoretical value were calculated and classified according to the time of the last meal of each rat (Fig. 3, lower panel). Relatively hungry animals which had not or hardly had taken any food (less than $0.5 \mathrm{~g} / 100 \mathrm{~g} \mathrm{BW}$ ) during a 3-hr period before decapitation appeared to differ significantly from the other animals in respect of NE uptake by caudal hypothalamus in vitro corrected for rate of food intake. Moreover, rats which had taken their last meal between 15 and $180 \mathrm{~min}$ before decapitation displayed a larger variation in corrected NE uptake values than animals which had been eating within the $15 \mathrm{~min}$ before decapitation. In fact, uncorrected hypothalamic NE uptake values obtained from the latter group of animals were highly correlated with the amounts of food eaten per unit of time $(r=0.966$, $p<0.001$ ) 


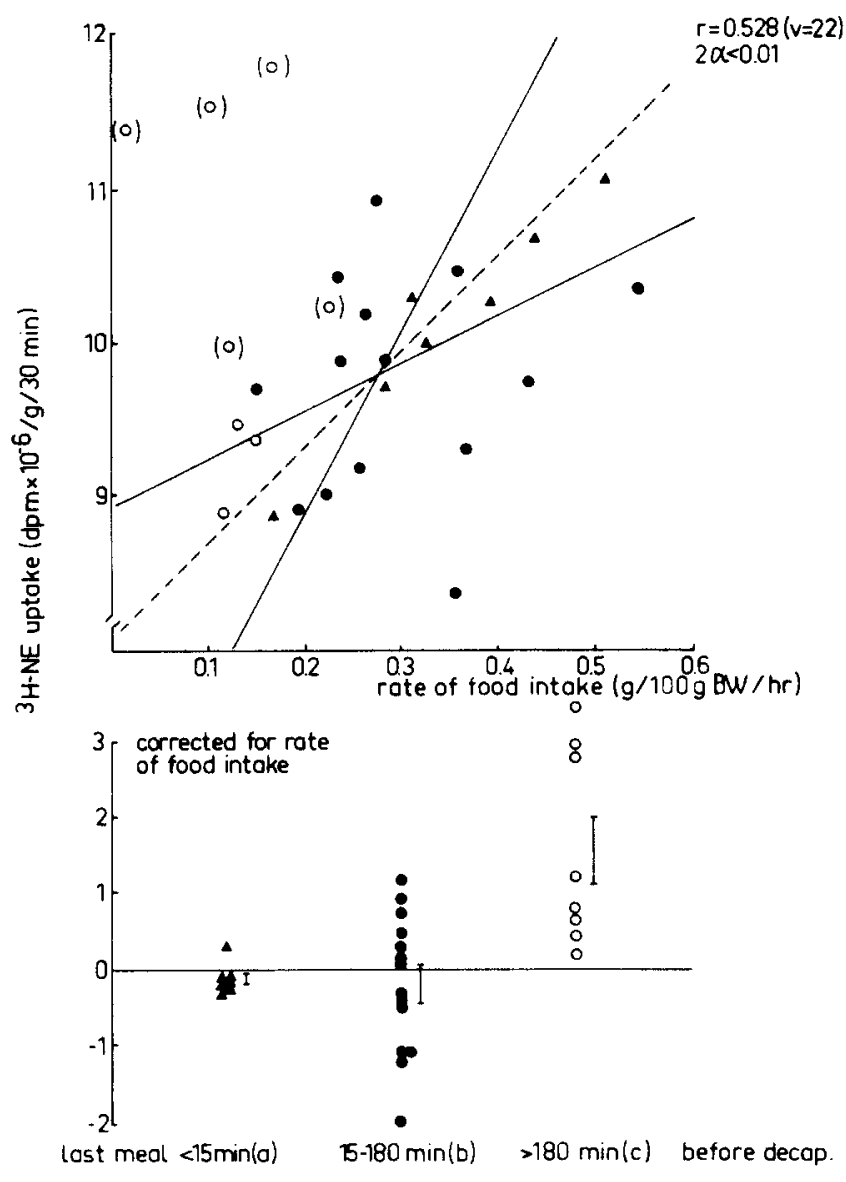

FIG. 3. Correlation between in vitro norepinephrine uptake by caudal hypothalamus from freely feeding rats and rate of food intake within a 2- to 4-hr interval (upper panel), and norepinephrine uptake corrected for rate of food intake classified according to the time elapsed after the last meal (lower panel). When no feeding had been observed during the last $3 \mathrm{hr}$, the corresponding animal was excluded from regression analysis (dots in parentheses). The baseline in the lower panel corresponds to the dashed line in the upper panel. a vs $\mathrm{b}: \mathrm{F}(6,13)=22.8, p<0.01$; $\mathrm{a}$ vs $\mathrm{c}$ : $p<0.01 ; \mathrm{b}$ vs c: $p<0.0025$.

\section{DISCUSSION}

Endogenous NE contents of rat midbrain [9] and hypothalamus [20] have been shown to vary within $24 \mathrm{hr}$. Such differences in NE concentration could result from variations in neuronal synthesis or metabolism and variations in release at synaptic endings or reuptake into nerve terminals. The latter process is thought to be the major mechanism for termination of the physiological action of released $\mathrm{NE}$ [15]. NE uptake by brain tissue in vitro has revealed regional differences in affinity for NE [26] which are in agreement with the anatomical distribution of catecholaminergic nerve terminals as shown by histochemical fluorescence studies [11]. NE uptake by brain tissue in vitro can also be inhibited by drugs which affect NE uptake and storage in vivo $[13,26,27]$. In addition, brain tissue in vitro displayed a reduction in NE uptake after chemical [28] and electrolytic lesioning of innervating NE axons
[31] or corresponding cell bodies [17]. Therefore, it can be assumed that the active accumulation of radioactivity taking place during the incubation of brain tissue with ${ }^{3} \mathrm{H}-\mathrm{NE}$ at relatively low concentration reflects the physiological process of inactivation of NE by the reuptake mechanism of aminergic nerve terminals.

In the present study, a diurnal rhythm in ${ }^{3} \mathrm{H}-\mathrm{NE}$ uptake by caudal hypothalamus in vitro has been demonstrated for freely feeding male rats (Fig. 1). The observed rhythm is in agreement with the rhythm in endogenous NE content of the same area in the hypothalamus of female rats housed under nearly identical lighting conditions [20], as far as the maximum at 21:00 hr and the minimum at 5:00 hr are concerned. However, the data on daily variations in hypothalamic NE content do not include a value at about 17:00 hr when hypothalamic NE uptake is also at a minimum. A similar analogy between a rhythm in endogenous transmitter level and periodicity in neuronal processes in vitro has been observed for hypothalamic serotonin (5-HT) [14].

In theory, a rhythm in dynamics of NE neurons can be related to a number of different behavioral, hormonal and metabolic parameters which show circadian rhythmicity. However, the daily variations in ${ }^{3} \mathrm{H}-\mathrm{NE}$ uptake by caudal hypothalamus in vitro highly correspond to the circadian fluctuations in spontaneous firing of those lateral hypothalamic neurons which are responsive to glucose injected into the hepatic portal vein [23]. As these neurons might participate in the regulation of food intake, this suggests that the observed fluctuations in hypothalamic NE uptake are at least in part correlated with feeding.

Another indication of a correlation between NE uptake and food intake is obtained from the observed effects of altered feeding conditions on the circadian uptake rhythm. NE uptake by caudal hypothalamus from relatively hungry rats accustomed to a 2 - or 8-hr feeding period during the daytime appears to be significantly increased in afternoon and evening compared with uptake by tissue from freely feeding animals (Figs. 1 and 2). However, no difference between NE uptake by caudal hypothalamus from rats maintained on an 8-hr feeding schedule and ad lib control values has been observed in the morning. The occurrence of a relative maximum in hypothalamic NE uptake at about 13:00 hr which does not correspond to an increase in food intake during this part of the day might also indicate that this parameter is not exclusively correlated with feeding throughout $24 \mathrm{hr}$. Rats which have been deprived of food only once for 23 or $28 \mathrm{hr}$ consume 40 percent of the stabilized intake of rats adjusted to a 22-hr deprivation schedule when free access to food is given for 2 hr during the afternoon; in other words, in that period these animals are less hungry than rats accustomed to a feeding schedule. This might explain why only a tendency towards increased uptake values has been observed after simple food deprivation (Fig. 2).

The present data on adrenal corticosteroid production in vitro suggest that neither stress factors nor pituitaryadrenocortical activity have induced the observed changes in hypothalamic NE uptake after food restriction because rats maintained on an 8-hr feeding schedule show a normal adrenocortical rhythm (Table 1). Moreover, no significant differences between plasma corticosterone levels in rats held on a 2-hr feeding schedule and plasma levels in freely feeding animals were detected [5].

Theoretically, the availability of catecholamine precursors is another factor which might have induced the 
observed changes in NE uptake because brain catechol synthesis in vivo was shown to be dependent on tyrosine concentration in rat brain [30], although a relatively small and hardly significant increase in catechol synthesis corresponded to a large increase in brain tyrosine level. However, even brain 5-HT levels which are much more dependent on levels of the precursor tryptophan [7] only appeared to be elevated after the consumption of diets consisting of pure carbohydrates [8] and were shown to be independent from daily changes in the intake of normal food [22]. Both these facts as well as the observation that brain tyrosine levels are much less altered than tryptophan levels after $24 \mathrm{hr}$ of food deprivation [4] suggest that the observed changes in hypothalamic NE uptake are not likely to be related to the availability of NE precursors.

From the observed variations in uptake within $24 \mathrm{hr}$ and the effects of food restriction on this daily rhythm, it might be concluded that NE uptake by caudal hypothalamus at least during late afternoon and early evening is related to feeding rate. Additional evidence for such a relation is to be found in the data obtained from freely feeding individual animals (Fig. 3, upper panel). Not only is there a correlation between hypothalamic NE uptake and mean rate of food intake, but also the time elapsed after the last meal seems to be a determinant of NE uptake (Fig. 3, lower panel). NE uptake into nerve terminals in caudal hypothalamus immediately after a meal appears to be highly correlated with feeding rate. From $15 \mathrm{~min}$ after the end of a meal probably a number of factors such as metabolism already exerts an influence on hypothalamic catecholaminergic neurons, appearing as a less significant correlation between NE uptake and rate of food intake. Approximately $3 \mathrm{hr}$ after the last meal caudal hypothalamic NE uptake clearly deviates from a theoretical value based on the mean rate of food intake, indicating that nonfeeding ultimately results in relatively high neuronal activity. These findings are in agreement with the hypothesis that the onset of each meal is dependent on a metabolic and humoral state related to the balance between the preceding caloric load and the current metabolic expenditure throughout the meal to meal interval [19] and they suggest a role of adrenoceptors in the series of events determining the consumption of an individual meal.

It can be concluded that differences in the activity of hypothalamic aminergic neurons which probably correspond to physiological changes in feeding behavior are detectable by measurement of NE uptake by brain tissue in an in vitro system. Another example of changes in catecholamine uptake in vitro which reflect in vivo alterations is the effect of ovarian steroids on hypothalamic NE and dopamine uptake [6]. It should be mentioned that hypothalamic NE levels in 22 [10], 31 or $55 \mathrm{hr}$ food deprived rats and in hungry rats maintained on a $2-h r$ feeding schedule (unpublished observations) are not altered when compared with ad lib control levels. However, studies involving inhibition of synthesis suggest that NE turnover in the hypothalamus of food deprived rats [10] and hungry rats adjusted to restricted feeding (unpublished data) is enhanced. The present study shows that caudal hypothalamic NE uptake in vitro is probably correlated with the feeding pattern of the rat at least during afternoon and evening.

\section{REFERENCES}

1. Björklund, A., A. Nobin and U. Stenevi. Effects of 5,6-dihydroxytryptamine on nerve terminal serotonin and serotonin uptake in the rat brain. Brain Res. 53: 117-127, 1973.

2. Booth, D. A. Localization of the adrenergic feeding system in the rat diencephalon. Science 158: 515-517, 1967.

3. Booth, D. A. Mechanism of action of norepinephrine in eliciting an eating response on injection into the rat hypothalamus. J. Pharmac. exp. Ther. 160: 336-348, 1968.

4. Curzon, G., M. H. Joseph and P. J. Knott. Effects of immobilization and food deprivation on rat brain tryptophan metabolism. J. Neurochem. 19: 1967-1974, 1972.

5. De Gasquet, P. and E. Pequignot. Changes in adipose tissue and heart lipoprotein activities and in serum glucose, insulin and corticosterone concentrations in rats adapted to a daily meal. Horm. Metab. Res. 5: 440-443, 1973.

6. Endersby, C. A. and C. Wilson. The effect of ovarian steroids on the uptake of ${ }^{3} \mathrm{H}$-noradrenaline, ${ }^{3} \mathrm{H}$-dopamine and ${ }^{3} \mathrm{H}$-5-hydroxytryptamine by hypothalamic tissue in vitro. $\mathrm{Br}$. J. Pharmac. 47: 647P-648P, 1973.

7. Fernstrom, J. D. and R. J. Wurtman. Brain serotonin content: physiological dependence on plasma tryptophan levels. Science 173: 149-152, 1971.

8. Fernstrom, J. D. and R. J. Wurtman. Brain serotonin content: physiological regulation by plasma neutral amino acids. Science 178: 414-416, 1972.

9. Friedman, A. H. and C. A. Walker. Circadian rhythms in rat midbrain and caudate nucleus biogenic amine levels. $J$. Physiol. 197: 77-85, 1968.

10. Friedman, E., N. Starr and S. Gershon. Catecholamine synthesis and the regulation of food intake in the rat. Life Sci. 12: $317-326,1973$.
11. Fuxe, K. Evidence for the existence of monoamine neurons in the central nervous system. IV. The distribution of monoamine nerve terminals in the central nervous system. Acta physiol. scand. suppl. 247, 64: 39-85, 1965.

12. Grossman, S. P. Eating and drinking elicited by direct adrenergic or cholinergic stimulation of hypothalamus. Science 132: 301-302, 1960.

13. Hamberger, B. Reserpine-resistant uptake of catecholamines in isolated tissues of the rat. Acta physiol. scand. suppl. 295, 71: $1-47,1967$.

14. Héry, F., E. Rouer and J. Glowinsky. Daily variations of serotonin metabolism in the rat brain. Brain Res. 43: $445-465,1972$.

15. Iversen, L. L. The Uptake and Storage of Noradrenaline in Sympathetic Nerves. New York: Cambridge University Press, 1967.

16. König, J. F. R. and R. A. Klippel. The Rat Brain. Baltimore: Williams and Wilkins Company, 1963.

17. Kuhar, M. J. Neurotransmitter uptake: a tool in identifying neurotransmitter-specific pathways. Life Sci. 13: 1623-1634, 1973.

18. Leibowitz, S. F. Hypothalamic beta adrenergic "satiety" system antagonizes an alpha adrenergic "hunger" system in the rat. Nature 226: 963-964, 1970.

19. Le Magnen, J., M. Devos, J.-P. Gaudilliére, J. Louis-Sylvestre and $\mathrm{S}$. Tallon. Role of a lipostatic mechanism in regulation by feeding of energy balance in rats. $J$. comp. physiol. Psychol. 84: 1-23, 1973.

20. Manshardt, J. and R. J. Wurtman. Daily rhythm in the noradrenaline content of rat hypothalamus. Nature 217: $574-575,1968$. 
21. Montgomery, R. B., G. Singer, A. T. Purcell, J. Narbeth and A. G. Bolt. Central control of hunger in the rat. Nature 223: $1278-1279,1969$.

22. Morgan, W. W. and C. A. Yndo. Daily rhythms in tryptophan and serotonin content in mouse brain: the apparent independence of these parameters from daily changes in food intake and from plasma tryptophan content. Life Sci. 12: 395-408, 1973.

23. Schmitt, M. Circadian rhythmicity in responses of cells in the lateral hypothalamus. Am. J. Physiol. 225: 1096-1101, 1973.

24. Slangen, J. L. The role of hypothalamic noradrenergic neurons in food intake regulation. In: Progress in Brain Research, Vol. 41, Integrative Hypothalamic Activity, edited by D. F. Swaab and J. P. Schadé. Amsterdam: Elsevier, 1974, pp. 395-407.

25. Slangen, J. L. and N. E. Miller. Pharmacological tests for the function of hypothalamic norepinephrine in eating behavior. Physiol. Behav. 4: 543-552, 1969.
26. Snyder, S. H., A. I. Green and E. D. Hendley. Kinetics of ${ }^{3} \mathrm{H}$-norepinephrine accumulation into slices from different regions of the rat brain. J. Pharmac. exp. Ther. 164: $90-102,1968$.

27. Taylor K. M. and S. H. Snyder. Amphetamine: differentiation by $d-$ and 1 isomers of behavior involving brain norepinephrine or dopamine. Science 168: 1487-1489, 1970.

28. Uretsky, N. J. and L. L. Iversen. Effects of 6-hydroxydopamine on noradrenaline-containing neurones in the rat brain. Nature 221: 557-559, 1969.

29. Vies, J. van der, R. F. M. Bakker and D. de Wied. Correlated studies on plasma free corticosterone and on adrenal steroid formation in vitro. Acta Endocr. 34: 513-523, 1960.

30. Wurtman, R. J., F. Larin, S. Mostafapour and J. D. Fernstrom. Brain catechol synthesis: control by brain tyrosine concentration. Science 185: 183-184, 1974.

31. Zigmond, M. J., J. P. Chalmers, J. R. Simpson and R. J Wurtman. Effect of lateral hypothalamic lesions on uptake of norepinephrine by brain homogenates. J. Pharmac. exp. Ther. 179: $20-28,1971$. 